\title{
Avaliação nutricional de pastagens de capim-elefante e capim-mombaça sob manejo rotacionado em diferentes períodos de ocupação ${ }^{1}$
}

\author{
Fábio Nunes Lista ${ }^{2}$, José Fernando Coelho da Silva ${ }^{3}$, Hernán Maldonado Vásquez ${ }^{3}$, Edenio \\ Detmann ${ }^{4}$, Afonso Aurélio de Carvalho Peres ${ }^{5}$
}

\footnotetext{
${ }^{1}$ Parte da dissertação do primeiro autor. Pesquisa financiada pelo CNPq e pela FAPERJ.

2 Doutorando em Produção Animal UENF/LZNA.

${ }^{3}$ LZNA/CCTA/UENF, Campos dos Goytacazes, RJ. Bolsista do CNPq

${ }^{4}$ DZO/UFV, Viçosa, MG. Bolsista do CNPq.

${ }^{5}$ APTA
}

RESUMO - A técnica de extrusa esofágica foi utilizada com o objetivo de avaliar qualitativamente pastagens de capim-elefante (Pennisetum purpureum Schum. cv. Napier) e capim-mombaça (Panicum maximum, cv. Mombaça) manejadas sob sistema rotacionado. As amostras relativas aos três primeiros dias de ocupação foram utilizadas para determinar os teores de MS, PB, EE, MO, lignina (LIG), FDN e FDA, a digestibilidade in vitro da MS (DIVMS) e o fracionamento dos carboidratos e proteínas, além do tempo de latência e da taxa de degradação dos carboidratos. As composições médias das amostras de extrusa esofágica obtidas nos dias sob pastejo foram comparadas por meio de contrastes ortogonais, com posterior ajuste de equações de regressão. Os teores de LIG e DIVMS diferiram apenas no capim-mombaça. Nesta espécie, houve aumento de 2,57 pontos percentuais nos teores da fração indigerível e redução de 3,23 pontos percentuais para os teores da fração potencialmente digestível dos carboidratos. Para cinética de degradação dos carboidratos fibrosos, verificou-se diferença apenas para o capim-mombaça, no qual houve redução linear. Tanto a fração insolúvel em detergente ácido quanto a fração protéica degradável dos capins elefante e mombaça apresentaram decréscimo linear com o passar dos dias sob pastejo.

Palavras-chave: extrusa esofágica, forrageira tropical, pastejo rotacionado

\section{Nutritional evaluation of elephantgrass and mombaçagrass pastures under rotational stocking as a function of different grazing periods}

\begin{abstract}
Qualitative assessment of elephantgrass (Pennisetum purpureum, Schum. cv. Napier) and mombaçagrass (Panicum maximum, cv. Mombaça) pastures under rotational stocking was performed using the esophageal extrusa technique. Samples of esophageal extrusa were taken at the third, second and first days of the grazing period. The following analyses were determined: DM, CP, EE, OM, lignin (LIG), NDF, ADF, in vitro dry matter digestibility (IVDMD), lag time and degradation rate of carbohydrates, and fractions of the carbohydrates and nitrogenous compounds. The average composition of extrusa samples as a function of the days under grazing were compared through orthogonal contrasts, with subsequent adjustment of regression equations. For IVDMD and LIG, differences were observed just for the mombaçagrass. For this species, an increase of 2.57 percentual points in the indigestible fraction (fraction C) and a reduction of 3.23 percentual points in the potential degradable fraction (B2) of carbohydrates were observed. For the kinetics of degradation, it was found difference just for the mombaçagrass, showing linear reduction in the rate of degradation of the fibrous carbohydrates. Both the acid detergent insoluble protein fraction and the protein degradable fraction of elephantgrass and mombaçagrass showed linear decrease with increasing grazing period.
\end{abstract}

Key Words: esophageal extrusa, rotational stocking, tropical forage

\section{Introdução}

As variações sazonais na disponibilidade e no valor nutritivo das forragens em regiões tropicais ocasionam aumento na idade de abate e redução no ganho de peso por animal e por área.
O conhecimento destas variações ao longo do período de maior crescimento vegetativo é fundamental para correção de deficiências específicas e maximização da utilização dos nutrientes neste período. Diversos fatores relacionados ao manejo da forrageira, como a idade de corte e a altura de corte ou de pastejo, entre outros, influenciam o aumento 
ou a queda da qualidade da forragem. Aumentar a qualidade da forragem disponível possibilita a redução dos custos de produção maximizando a produtividade. Além disso, é preciso entender o que é qualidade da forragem e quais fatores afetam esta qualidade (Morenz, 2000).

Períodos de descanso para recompor as reservas das forragens podem ser obtidos com a adoção do pastejo rotacionado, caracterizado pela mudança periódica e freqüente dos animais de um piquete para o outro, de forma a completar um ciclo de pastejo (Rodrigues \& Reis, 1997).

A dieta selecionada pelos animais pode ser influenciada pela taxa de lotação, que implica variações no comportamento seletivo dos animais. Taxas de lotação mais baixas possibilitam aos animais selecionarem dieta de melhor qualidade, ao passo que, em lotações mais elevadas, esta possibilidade se torna limitada, forçando os animais a consumirem plantas ou partes de plantas antes não consumidas (Araújo, 1985).

Todavia, a taxa de lotação por área está diretamente relacionada à disponibilidade e ao estabelecimento de forragem e reflete na pressão de pastejo sobre a área, interferindo no desempenho dos animais e na longevidade da pastagem, tornando necessária a utilização de estratégias de manejo para o máximo aproveitamento da forragem.

Clipes (2003), analisando a qualidade da extrusa esofágica em um sistema rotacionado em pastagens de capim-mombaça, observou redução na qualidade da forragem com o avanço no período de ocupação. Em parte, esse resultado decorreu do acréscimo dos constituintes da parede celular (Van Soest, 1994) após o início do pastejo e que compromete a produção animal.

Neste trabalho, avaliaram-se qualitativamente as variações da composição químico-bromatológica, a digestibilidade in vitro da MS (DIVMS), o fracionamento da proteína e dos carboidratos e a degradabilidade dos carboidratos do material coletado via extrusa esofágica de pastagens formadas por capim-elefante (Pennisetum purpureum, Schum. cv. Napier) e capim-mombaça (Panicum maximum, Jacq. cv. Mombaça) manejadas sob pastejo rotacionado.

\section{Material e Métodos}

As amostras foram coletadas em sistemas de pastejo rotacionado, em 15 piquetes de capim-elefante (Pennisetum purpureum, Schum cv. Napier) e 13 de capim-mombaça (Panicum maximum, Jacq cv. Mombaça), com período de ocupação de três dias e descanso de 42 e 36 dias, respectivamente. Os piquetes de ambas as forrageiras apresentavam área de $600 \mathrm{~m}^{2}$.
As forragens foram avaliadas qualitativamente por meio de amostras de extrusa esofágica entre os meses de setembro e dezembro de 2002, totalizando dois ciclos completos de pastejo para ambas as forrageiras.

As coletas foram realizadas seqüencialmente em cada piquete ocupado, alternando-se, no entanto, o momento da amostragem, de modo que, a cada grupo de três piquetes pastejados, foram obtidas amostras referentes ao terceiro, segundo e primeiro dias de ocupação. As coletas de extrusa esofágica foram realizadas com dois novilhos mestiços Holandês-Zebu, com 420 kg de PV, fistulados no esôfago, utilizando-se um animal por forrageira, casualizados anteriormente a cada coleta.

Na noite anterior a cada coleta, os animais foram submetidos a jejum por aproximadamente 12 horas (Holecheck, 1982). Na manhã seguinte, foram conduzidos até a área experimental para retirada das cânulas e instalação das bolsas coletoras, confeccionadas em lona impermeável e com fundo telado para a coleta de extrusa esofágica.

As amostras de extrusa foram colocadas em sacos plásticos identificados e armazenadas em congelador a $-15^{\circ} \mathrm{C}$ para análises laboratoriais. Posteriormente, as amostras foram descongeladas a temperatura ambiente e secas em estufa de ventilação forçada $\left(60^{\circ} \mathrm{C}, 72\right.$ horas). Em seguida, foram trituradas em moinho de faca com peneira com porosidade de $1 \mathrm{~mm}$ e acondicionadas em frascos de vidro com tampa de polietileno. Foram estimados os teores de MS, MO, PB e EE, segundo técnicas descritas por Silva (1990), lignina (LIG), segundo Rowland \& Roberts (1994), fibra em detergente neutro corrigida para cinza e proteína ( $\mathrm{FDN}_{\mathrm{CP}}$ ) e FDA, conforme descrito por Sniffen et al. (1992).

As frações dos compostos nitrogenados $(\mathrm{N})$ foram estimadas de acordo com padronizações postuladas por Licitra et al. (1996). A fração A ou nitrogênio não-protéico (NNP) foi calculada pela diferença entre o teor de $\mathrm{N}$-total e o de $\mathrm{N}$-insolúvel no TCA. A fração $\mathrm{B}_{3}$ ou proteína insolúvel em detergente neutro potencialmente degradável foi obtida pela diferença entre o $\mathrm{N}$-insolúvel em detergente neutro (NIDN) e o N-insolúvel em detergente ácido (NIDA), estimados segundo padronizações de Sniffen et al. (1992), e a fração C ou proteína insolúvel em detergente ácido, pela determinação de N-insolúvel em detergente ácido (NIDA) (Licitra et al., 1996).

A fração $B_{1}+B_{2}$ foi obtida por diferença, conforme adaptação da fórmula de Sniffen et al. (1992), em que: $\left(\mathrm{B}_{1}+\mathrm{B}_{2}\right)=100-\left(\mathrm{A}+\mathrm{B}_{3}+\mathrm{C}\right)$.

Para todas as frações, empregou-se o fator multiplicativo 6,25 para expressão dos teores em termos de equivalentes protéicos. 
Os CT foram calculados conforme Sniffen et al. (1992), em que: $\mathrm{CT}(\% \mathrm{MS})=100-\mathrm{PB}-\mathrm{EE}-$ cinzas .

As frações $A+B_{1}$, agrupadas como carboidratos nãofibrosos (CNF), foram calculadas segundo Weiss (1999), em que: $\mathrm{CNF}(\%)=100$ - cinzas $-\mathrm{PB}-\mathrm{EE}-\mathrm{FDN}_{\mathrm{CP}}$, em que $\mathrm{FDN}_{\mathrm{CP}}$ representa a parede celular vegetal isenta de cinzas e proteínas.

A estimativa da fração C ou FDAi foi obtida a partir da fórmula citada por Sniffen et al. (1992), que se baseia na concentração da lignina multiplicada pela constante 2,4. Por outro lado, a fração $\mathrm{B}_{2}$, composta de FDN potencialmente degradável, foi obtida a partir da subtração da fração $C$ do teor da $\mathrm{FDN}_{\mathrm{CP}}$, ou seja: $\mathrm{B}_{2}=\mathrm{FDN}_{\mathrm{CP}}-\mathrm{C}$.

A digestibilidade in vitro da MS (DIVMS) nas amostras de extrusa foi estimada utilizando-se líquido ruminal de um novilho mestiço mantido em pastagem segundo metodologia descrita por Tilley \& Terry (1963).

A avaliação da cinética de degradação ruminal dos carboidratos foi realizada pela mensuração da produção cumulativa de gases in vitro. Tomaram-se duas alíquotas de aproximadamente $100 \mathrm{mg}$ de MS de cada amostra, as quais foram acondicionadas em frascos de vidro com $50 \mathrm{~mL}$ de volume total, aos quais foram adicionados, imediatamente, $8 \mathrm{~mL}$ de solução tampão de McDougall (McDougall,1949) com pH previamente ajustado em 6,8 por meio de aspersão de $\mathrm{CO}_{2}$. Os frascos foram acondicionados em "banho-maria” por aproximadamente 30 minutos, tempo necessário para estabilização da temperatura e hidratação das amostras. Paralelamente, durante este processo, procedeu-se à coleta de líquido ruminal em um animal mantido em condições semelhantes àquelas para avaliação da DIVMS. Após filtragem em camada tríplice de gaze, o líquido foi acondicionado em recipiente térmico e imediatamente conduzido ao local de incubação.

Os frascos contendo as amostras e a solução tampão foram adicionados de $2 \mathrm{~mL}$ do inóculo ruminal e imediatamente vedados com tampas de borracha e lacres de alumínio, sendo recolocados em "banho-maria" com agitação constante. As leituras foram feitas 1, 2, 3, 4, 5, 6, 8, 10, 12, 15, 24, 27, 30, 33, 36, 48, 56, 60, 72, 96 e 120 horas após o início da incubação utilizando-se uma agulha de seringa acoplada a um transdutor eletrônico ligado diretamente a um multímetro. Neste procedimento, a pressão no interior dos frascos, formada pelo acúmulo dos gases, foi medida, com o auxílio do transdutor, em unidades elétricas ( $\mathrm{mV}$ ), as quais foram posteriormente convertidas em volume de gás (mL) por meio do procedimento descrito por Pell \& Schofield (1993). Os volumes obtidos nesses intervalos de leitura foram adicionados seqüencialmente de modo a se obter, em determinado tempo, a produção acumulada de gases.
Por meio do procedimento iterativo de Gauss-Newton (Souza,1998), procedeu-se ao ajustamento do modelo logístico bi-compartimental descrito por Schofield et al. (1994):

$V t=V f_{1}\left\{1+\exp \left[2+4 \frac{\mu m_{1}}{V f_{1}}(L-t)\right]\right\}^{-1}+V f_{2}\left\{1+\exp \left[2+4 \frac{\mu m_{2}}{V f_{2}}(L-t)\right]\right\}^{-1}$

em que: $\mathrm{Vt}$ = volume acumulado de gases no tempo " $\mathrm{t}$ ” $(\mathrm{mL})$; $\mathrm{Vf}=$ volume total de gases produzidos em $\mathrm{t} \rightarrow \infty(\mathrm{mL}) ; \mu \mathrm{m}=$ taxa máxima de produção de gases $\left(\mathrm{mL} \cdot \mathrm{h}^{-1}\right)$; $\mathrm{L}=$ latência $(\mathrm{h})$; $\mathrm{t}$ = tempo após o início da incubação (h); e “” ” e “” " indicadores referentes à cinética de produção de gases a partir de CF e CNF, respectivamente.

A razão $\mu \mathrm{m} / \mathrm{Vf}$, a qual apresenta a unidade $\mathrm{h}^{-1}$, representa a taxa específica de digestão ( $\mathrm{kd}$ ) do substrato (Schofield et al., 1994).

As comparações entre médias de dias de pastejo foram realizadas por meio da decomposição da soma de quadrados associada a esta fonte de variação em contrastes ortogonais com posterior ajuste de equações de regressão linear.

\section{Resultados e Discussão}

Os teores de MS, tanto para o capim-elefante quanto para o capim-mombaça decresceram linearmente $(\mathrm{P}<0,05)$ (Tabela 1). No caso do capim-elefante, os teores de MO, PB e EE não diferiram $(P>0,05)$ entre os dias sob pastejo (Tabela 1). No capim-mombaça, no entanto, os teores de MO e PB apresentaram diferenças significativas $(P<0,05)$, com redução linear de 0,93 pontos percentuais por dia sob pastejo para os teores de $\mathrm{PB}$ e um comportamento quadrático para os teores de MO.

Os teores de FDN e FDA das forrageiras analisadas (Tabela 2), tanto do capim-elefante quanto do capimmombaça, não diferiram $(\mathrm{P}>0,05)$ entre os dias de pastejo e foram similares aos descritos por Clipes (2003), que, avaliando uma pastagem de capim-elefante, considerou a amostragem do primeiro dia representativa dos demais dias sob pastejo quando os piquetes manejados apresentaram as mesmas condições.

O aumento linear $(\mathrm{P}<0,05)$ nos teores de lignina (Tabela 2) no capim-mombaça com o avanço do período de ocupação compromete a qualidade da forrageira pastejada, uma vez que a lignina está associada à indigestibilidade dos componentes da parede celular (Van Soest, 1994).

A digestibilidade (Tabela 2) do capim-mombaça sofreu variação $(\mathrm{P}<0,05)$ entre os dias de pastejo, indicando que o acúmulo de MS, que ocorre principalmente na parede celular (Van Soest, 1994), acompanhado pelo aumento nos teores de lignina, influencia o material de acordo com o dia avaliado 
Tabela 1 - Concentrações de nutrientes em pastagens de capim-mombaça e capim-elefante em diferentes dias de pastejo Table 1 - Nutrient concentration in mombaçagrass and elephantgrass as a function of the number of days under grazing

\begin{tabular}{|c|c|c|c|c|c|c|c|c|c|c|}
\hline \multirow[b]{2}{*}{$\begin{array}{l}\text { Nutriente (\%MS) } \\
\text { Nutrient (\%DM) }\end{array}$} & \multicolumn{3}{|c|}{$\begin{array}{l}\text { Dias em pastejo } \\
\text { Days under grazing }\end{array}$} & \multirow[b]{2}{*}{ CV\% } & \multicolumn{2}{|c|}{$\begin{array}{l}\text { Valor } \mathrm{P} \\
P \text { value }\end{array}$} & \multicolumn{3}{|c|}{$\begin{array}{l}\text { Estimativa } \\
\text { Estimate }\end{array}$} & \multirow[b]{2}{*}{$\mathrm{r}^{2} / \mathrm{R}^{2}$} \\
\hline & 1 & 2 & 3 & & $\mathrm{~L}$ & $\mathrm{Q}$ & b0 & b1 & b2 & \\
\hline \multicolumn{11}{|l|}{$\begin{array}{l}\text { Capim-elefante } \\
\text { Elephantgrass }\end{array}$} \\
\hline \multicolumn{11}{|l|}{$\begin{array}{l}\text { Capim-mombaça } \\
\text { Mombaçagrass }\end{array}$} \\
\hline $\begin{array}{l}\text { MS (DM) } \\
\text { MO (OM) } \\
\mathrm{PB}(C P) \\
\mathrm{EE}(E E)\end{array}$ & $\begin{array}{r}15,38 \\
88,66 \\
12,72 \\
0,95\end{array}$ & $\begin{array}{r}14,35 \\
86,84 \\
10,33 \\
0,94\end{array}$ & $\begin{array}{r}13,5 \\
88,85 \\
10,87 \\
1,28\end{array}$ & $\begin{array}{r}7,8 \\
1,2 \\
9,6 \\
40,34\end{array}$ & $\begin{array}{l}0,0456 \\
0,8096 \\
0,0419 \\
0,2921\end{array}$ & $\begin{array}{l}0,8965 \\
0,0209 \\
0,0583 \\
0,5154\end{array}$ & $\begin{array}{r}16,29 \\
94,31 \\
13,16 \\
1,06\end{array}$ & $\begin{array}{c}-0,9431 \\
-7,5698 \\
-0,9273 \\
-\end{array}$ & $\begin{array}{c}- \\
1,9164 \\
- \\
-\end{array}$ & $\begin{array}{c}0,4116 \\
0,5089 \\
0,4225 \\
-\end{array}$ \\
\hline
\end{tabular}

${ }^{1} \mathrm{~L}$ e Q - efeitos linear e quadrático para o número de dias sob pastejo, respectivamente ( $\mathrm{L}$ and $Q$ - linear and quadratic effect for number of days under grazing, respectively). CV: coeficiente de variação (coefficient of variation).

$r^{2} / R^{2}$ : estimativas dos parâmetros de regressão e coeficiente de determinação $\left(r^{2} / R^{2}\right.$ - estimate of regression parameters and coefficients of determination)

e, conseqüentemente, promove diminuição da ação enzimática da microbiota ruminal sobre os carboidratos estruturais (Moore \& Mott, 1973).

Para o capim-mombaça, verificaram-se redução linear $(\mathrm{P}<0,05)$ de 3,23 pontos percentuais ao dia na fração $\mathrm{B}_{2} \mathrm{e}$ aumento de 2,57 pontos percentuais da fração C, comprovando redução na qualidade da forrageira com o passar dos dias sob pastejo. Possivelmente, houve aumento dos consti- tuintes da parede celular, aumentando os tecidos estruturais, e redução na relação folha/colmo durante a coleta do material nos diferentes dias, o que indica redução no valor nutritivo da forrageira (Tabela 1 ).

Os resultados encontrados neste estudo confirmam relatos de Machado et al. (1998) de que cultivares de Pannicum maximum apresentam menores teores de PB quando reduz a relação folha/colmo.

Tabela 2 - Concentrações de nutrientes (\%MS) e digestilidade in vitro da MS (DIVMS), em \%, de pastagens de capim-elefante e capimmombaça em diferentes dias sob pastejo

Table 2 - Nutrient concentrations (\%DM) and in vitro DM digestibility (IVDMD) of elephantgrass and mombaçagrass as a function of the number of days undergrazing

\begin{tabular}{|c|c|c|c|c|c|c|c|c|c|c|}
\hline \multirow[b]{2}{*}{$\begin{array}{l}\text { Nutriente (\%MS) } \\
\text { Nutrient (\%DM) }\end{array}$} & \multicolumn{3}{|c|}{$\begin{array}{l}\text { Dias em pastejo } \\
\text { Days under grazing }\end{array}$} & \multirow[b]{2}{*}{ CV\% } & \multicolumn{2}{|c|}{$\begin{array}{l}\text { Valor } \mathrm{P} \\
P \text { value }\end{array}$} & \multicolumn{3}{|c|}{$\begin{array}{l}\text { Estimativa } \\
\text { Estimate }\end{array}$} & \multirow[b]{2}{*}{$\mathrm{r}^{2} / \mathrm{R}^{2}$} \\
\hline & 1 & 2 & 3 & & $\mathrm{~L}$ & $\mathrm{Q}$ & b0 & b1 & b2 & \\
\hline
\end{tabular}

Capim-elefante

Elephantgrass

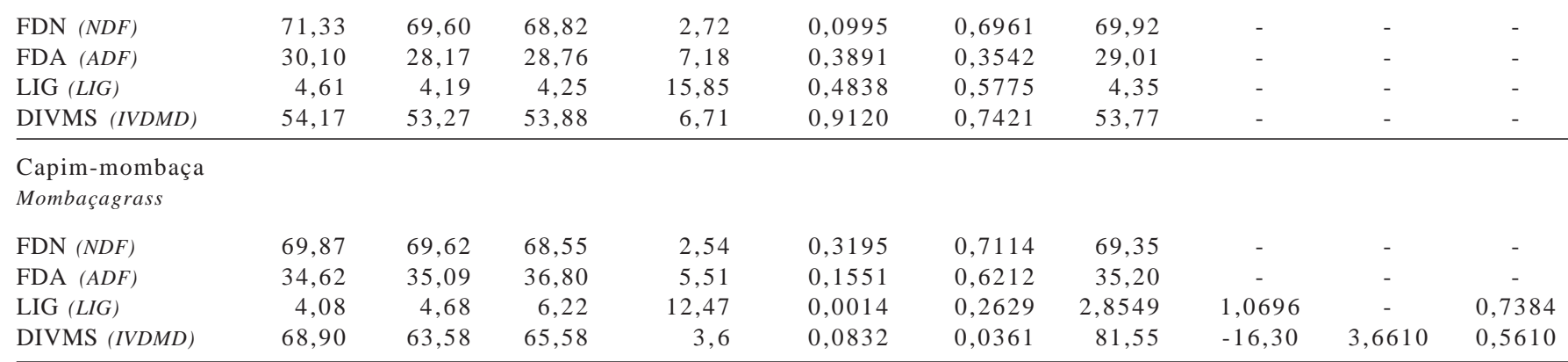

${ }^{1} \mathrm{~L}$ e Q - efeitos linear e quadrático para o número de dias sob pastejo, respectivamente ( $\mathrm{L}$ and Q - linear and quadratic effect for number of days under grazing, respectively). CV: coeficiente de variação (coefficient of variation).

$r^{2} / R^{2}$ : estimativas dos parâmetros de regressão e coeficiente de determinação $\left(r^{2} / R^{2}\right.$ - estimate of regression parameters and coefficients of determination) 
Tabela 3 - Concentrações de CT e CNF, frações $B_{2}$ e $C$ em pastagens de capim-elefante e capim-mombaça em diferentes dias sob pastejo Table 3 - Total carbohydrate concentrations (TC) and NFC, fractions B2, and C of elephantgrass and mombaçagrass as a function of the number of days undergrazing

\begin{tabular}{|c|c|c|c|c|c|c|c|c|c|c|}
\hline \multirow[t]{2}{*}{ Item } & \multicolumn{3}{|c|}{$\begin{array}{l}\text { Dias em pastejo } \\
\text { Days under grazing }\end{array}$} & & \multicolumn{2}{|c|}{$\begin{array}{l}\text { Valor } \mathrm{P} \\
P \text { value }\end{array}$} & \multicolumn{3}{|c|}{$\begin{array}{l}\text { Estimativa } \\
\text { Estimate }\end{array}$} & \multirow[b]{2}{*}{$r^{2} / R^{2}$} \\
\hline & 1 & 2 & 3 & CV\% & $\mathrm{L}$ & $\mathrm{Q}$ & b0 & b1 & b2 & \\
\hline
\end{tabular}

\section{Capim-elefante}

Elephantgrass

\begin{tabular}{lrrrrrrrrrrr} 
CT (TC) & 77,23 & 79,80 & 79,30 & 1,61 & 0,0504 & 0,0832 & 78,78 & - & - & - \\
CNF (NFC) & 5,90 & 10,19 & 10,47 & 28,56 & 0,0380 & 0,2315 & 4,2939 & 2,2832 & - & 0,4486 \\
$\mathrm{~B}_{2}$ & 60,25 & 59,55 & 58,61 & 4,08 & 0,3668 & 0,9401 & 59,47 & - & - & - \\
C & 11,07 & 10,05 & 9,80 & 15,85 & 0,4838 & 0,5775 & 10,31 & - & - \\
\hline
\end{tabular}

Capim-mombaça

Mombaçagrass

\begin{tabular}{|c|c|c|c|c|c|c|c|c|c|c|}
\hline $\mathrm{CT}(\mathrm{TC})$ & 74,98 & 75,56 & 76,69 & 1,71 & 0,1004 & 0,7411 & 75,74 & - & - & - \\
\hline CNF (NFC) & 5,11 & 5,93 & 8,13 & 39,07 & 0,1249 & 0,6650 & 6,39 & - & - & - \\
\hline $\mathrm{B}_{2}$ & 60,08 & 58,39 & 53,62 & 4,34 & 0,0063 & 0,3422 & 63,82 & $-3,2287$ & - & 0,6265 \\
\hline $\mathrm{C}^{2}$ & 9,79 & 11,23 & 14,92 & 12,74 & 0,0014 & 0,2629 & 6,8517 & 2,5671 & - & 0,7384 \\
\hline
\end{tabular}

${ }^{1} \mathrm{~L}$ e Q - efeitos linear e quadrático para o número de dias sob pastejo, respectivamente ( $\mathrm{L}$ and $Q$ - linear and quadratic effect for number of days under grazing, respectively). CV: coeficiente de variação (coefficient of variation).

$r^{2} / R^{2}$ : estimativas dos parâmetros de regressão e coeficiente de determinação $\left(r^{2} / R^{2}\right.$ - estimate of regression parameters and coefficients of determination)

Tabela 4 - Taxa de degradação $\left(\mathrm{k}-\mathrm{h}^{-1}\right)$, volume final de gás $(\mathrm{V}-\mathrm{mL})$ para carboidratos fibrosos (1) e não-fibrosos (2) e tempo de latência (LAT) em capim-elefante e capim-mombaça sob pastejo

Table 4 - Degradation rate $\left(k 2-h^{-1}\right)$ and final gas volume $(V-m L)$ for fibrous carbohydrates (1) and non-fibrous carbohydrates (2) and latency time (LAT) in elephantgrass and mombaçagrass as a function of the number days under grazing

\begin{tabular}{|c|c|c|c|c|c|c|c|c|c|c|}
\hline \multirow[t]{2}{*}{ Item } & \multicolumn{3}{|c|}{$\begin{array}{l}\text { Dias em pastejo } \\
\text { Days under grazing }\end{array}$} & & \multicolumn{2}{|c|}{$\begin{array}{l}\text { Valor } P \\
P \text { value }\end{array}$} & \multicolumn{3}{|c|}{$\begin{array}{l}\text { Estimativa } \\
\text { Estimate }\end{array}$} & \multirow[b]{2}{*}{$\mathrm{r}^{2} / \mathrm{R}^{2}$} \\
\hline & 1 & 2 & 3 & CV\% & $\mathrm{L}$ & $\mathrm{Q}$ & b0 & b1 & b2 & \\
\hline
\end{tabular}

Capim-elefante

Elephantgrass

\begin{tabular}{lrrrrrrrrr}
$\mathrm{K}_{1}$ & 0,0237 & 0,0212 & 0,0214 & 17,68 & 0,4393 & 0,5820 & 0,0221 & - & - \\
$\mathrm{K}_{2}$ & 0,1259 & 0,0954 & 0,1254 & 59,92 & 1,0000 & 0,4692 & 0,1042 & - & - \\
$\mathrm{V}_{1}$ & 15,38 & 14,78 & 14,93 & 18,93 & 0,8269 & 0,8320 & 15,03 & - & - \\
$\mathrm{V}_{2}$ & 6,14 & 7,29 & 7,94 & 41,39 & 0,4125 & 0,8937 & 7,12 & - & - \\
$\mathrm{LAT}$ & 8,72 & 9,85 & 8,40 & 16,88 & 0,2036 & 0,2036 & 8,99 & - & - \\
\hline
\end{tabular}

Capim-mombaça

Mombaçagrass

\begin{tabular}{lrrrrrrrrrr}
$\mathrm{K}_{1}$ & 0,0236 & 0,0219 & 0,0204 & 8,23 & 0,0393 & 0,9309 & 0,0214 & $-15,75$ & - & 0,4306 \\
$\mathrm{~K}_{2}$ & 0,1214 & 0,1211 & 0,0631 & 78,43 & 0,3319 & 0,5715 & 0,0912 & - & - & - \\
$\mathrm{V}_{1}$ & 12,85 & 13,30 & 13,28 & 10,02 & 0,6530 & 0,7755 & 13,14 & - & - \\
$\mathrm{V}_{2}$ & 8,05 & 6,03 & 5,85 & 30,56 & 0,1629 & 0,4802 & 6,64 & - & - & - \\
$\mathrm{LAT}$ & 8,74 & 10,84 & 11,47 & 16,02 & 0,0478 & 0,4881 & 7,6183 & 1,3675 & - & 0,4052 \\
\hline
\end{tabular}

${ }_{1} \mathrm{~L}$ e Q - efeitos linear e quadrático para o número de dias sob pastejo, respectivamente ( $L$ and $Q$ - linear and quadratic effect for number of days under grazing, respectively). $\mathrm{CV}$ : coeficiente de variação (coefficient of variation).

$r^{2} / R^{2}$ : estimativas dos parâmetros de regressão e coeficiente de determinação $\left(r^{2} / R^{2}\right.$ - estimate of regression parameters and coefficients of determination).

No capim-mombaça, a taxa de degradação da fração fibrosa $\left(\mathrm{K}_{1}\right)$ apresentou tendência linear $(\mathrm{P}<0,05)$ de redução (Tabela 4), o que pode estar associado ao aumento da fração indigerível (Tabela 3), comprovando tendência de queda da qualidade da forrageira com o passar dos dias sob pastejo. No capim-elefante, somente o tempo de latência (LAT) aumentou linearmente $(\mathrm{P}<0,05)$ com avanço dos dias sob pastejo.
Os compostos nitrogenados (Tabela 5) diferiram $(\mathrm{P}<0,05)$ apenas para a fração $\mathrm{C}$ do capim-elefante e para a fração $\mathrm{B}_{1}+\mathrm{B}_{2}$ do capim-mombaça, as quais apresentaram tendência linear, diminuindo com o passar dos dias sob pastejo.

O capim-elefante durante 42 dias de descanso apresentou grande quantidade de folhas novas (rebrota) que eram selecionadas pelo animal em pastejo. A diminuição da 
Tabela 5 - Concentrações das frações dos compostos nitrogenados em pastagens de capim-elefante e capim-mombaça sob pastejo Table 5 - Concentrations of the nitrogen compound fractions in elephant grass and mombaça grass as a function of the number of days under grazing

\begin{tabular}{|c|c|c|c|c|c|c|c|c|c|c|}
\hline \multirow[t]{2}{*}{ Item } & \multicolumn{3}{|c|}{$\begin{array}{l}\text { Dias em pastejo } \\
\text { Days under grazing }\end{array}$} & \multirow[b]{2}{*}{ CV\% } & \multicolumn{2}{|c|}{$\begin{array}{l}\text { Valor } \mathrm{P} \\
P \text { value }\end{array}$} & \multicolumn{3}{|c|}{$\begin{array}{c}\text { Estimativa } \\
\text { Estimate }\end{array}$} & \multirow[b]{2}{*}{$\mathrm{r}^{2} / \mathrm{R}^{2}$} \\
\hline & 1 & 2 & 3 & & $\mathrm{~L}$ & $\mathrm{Q}$ & b0 & b1 & b2 & \\
\hline
\end{tabular}

Capim-elefante

Elephantgrass

\begin{tabular}{lllllllllll}
$\mathrm{A}$ & 0,68 & 0,95 & 1,15 & 63,10 & 0,2836 & 0,9190 & 0,93 & - & - \\
$\mathrm{B}_{1}+\mathrm{B}_{2}$ & 6,73 & 5,69 & 5,94 & 11,80 & 0,1629 & 0,1832 & 6,12 & - & - \\
$\mathrm{B}_{3}$ & 2,29 & 2,35 & 2,35 & 19,51 & 0,8603 & 0,9190 & 2,33 & - & - & - \\
$\mathrm{C}$ & 1,38 & 1,11 & 1,05 & 15,03 & 0,0296 & 0,3525 & 15,15 & $-0,1661$ & - & 0,4659 \\
\hline
\end{tabular}

Capim-mombaça

Mombaçagrass

\begin{tabular}{lrrrrrrrrrrr}
$\mathrm{A}$ & 2,06 & 1,41 & 1,59 & 33,73 & 0,2750 & 0,2691 & 1,69 & - & - & - \\
$\mathrm{B}_{1}+\mathrm{B}_{2}$ & 6,67 & 5,68 & 5,51 & 11,40 & 0,0429 & 0,3509 & 6,12 & $-0,5786$ & - & 0,4192 \\
$\mathrm{~B}_{3}$ & 2,69 & 1,94 & 2,33 & 26,21 & 0,4305 & 0,1731 & 2,32 & - & - & - \\
$\mathrm{C}$ & 1,27 & 1,29 & 1,42 & 9,55 & 0,1515 & 0,4700 & 1,32 & - & - & - \\
\hline
\end{tabular}

${ }^{1} \mathrm{~L}$ e Q - efeitos linear e quadrático para o número de dias sob pastejo, respectivamente ( $L$ and $Q$ - linear and quadratic effect for number of days under grazing, respectively). $\mathrm{CV}$ : coeficiente de variação (coefficient of variation).

$r^{2} / R^{2}$ : estimativas dos parâmetros de regressão e coeficiente de determinação $\left(r^{2} / R^{2}\right.$ - estimate of regression parameters and determination coefficients).

relação folha/colmo observada no capim-mombaça pode, em parte, justificar a qualidade da proteína nas amostras de extrusa nos dias sob pastejo.

Verificou-se para o capim-mombaça redução no teor da fração $B_{1}+B_{2}$ em torno de 0,58 pontos percentuais (Tabela 5) a cada dia de pastejo. De qualquer modo, mesmo no terceiro dia de pastejo, o nível de PB desta forrageira manteve-se acima do nível mínimo recomendado para não haver redução nem comprometimento da digestibilidade dos nutrientes, pois, segundo Raymond (1969), a digestibilidade em forrageiras tropicais reduz se a concentração de PB se mantiver em 4 a 6\% da MS.

Entretanto, ressalta-se a fração da proteína disponível em relação ao total de PB ingerida, pois o comprometimento da atividade microbiana pode estar relacionado à quantidade de $\mathrm{N}$ disponível, ou seja, à fração da proteína que estará disponível para o desenvolvimento da microbiota ruminal (Van Soest, 1994).

\section{Conclusões}

Com o manejo adotado, a qualidade do capim-elefante foi pouquíssimo afetada pelos dias de ocupação, indicando que a metodologia para amostragem desta forrageira não depende do dia de avaliação.

A qualidade do capim-mombaça reduziu com o passar dos dias sob pastejo. Portanto, dependendo do manejo, avaliações diárias podem possibilitar maior confiança quanto à qualidade desta forrageira.

\section{Literatura Citada}

ARAÚJO, M.R. Dietary selection by cattle as influenced by stocking rates in a short-duration grazing system. Texas: College Station, Texas A\&M University, 1985. 186p.

CLIPES, R.C. Métodos de amostragem qualitativa e composição químico-bromatológica de forrageiras tropicais sob pastejo rotacionado. Campos dos Goytacazes: Universidade Estadual do Norte Fluminense, 2003. 69p. Dissertação (Mestrado em Produção Animal) - Universidade Estadual do Norte Fluminense, 2003.

CÓSER, A.C.; MARTINS, C.E.; ALVIM, M.J. Efeitos de diferentes períodos de ocupação em pastagens de capim-elefante sobre a produção de leite In: REUNIÃO ANUAL DA SOCIEDADE BRASILEIRA DE ZOOTECNIA, 33., 1996, Fortaleza. Anais... Fortaleza: Sociedade Brasileira de Zootecnia, 1996. p.174-176.

HOLECHECK, J.L.; VAVRA, M.; PIEPER, R.D. Methods for determining the nutritive quality of range ruminant diets: a review. Journal Animal Science, v.54, p.363-375, 1982.

JOHNSON, A.D. Sample preparation and chemical analysis of vegetation. In: MANNETJE, L.T. (Ed.) Measurement of grassland vegetation and animal production. Aberystwyth: Commonwealth Agricultural Bureaux, 1978. p.96-102.

LICITRA, G.; HERNANDEZ, T.M.; Van SOEST, P.J. Standardization of procedures for nitrogen fractionation of ruminant feeds. Animal Feed Science and Technology, v.57, p.347-358, 1996.

MACHADO, A.O.; CECATO, U.; MIRA, R.T. et al. Avaliação da composição químico-bromatológica e digestibilidade in vitro da matéria seca de cultivares de Panicumm maximum Jacq. sob duas alturas de corte. Revista Brasileira de Zootecnia, v.27, n.5, p.1057-1063, 1998.

McDOUGALL, E.I. Studies on ruminant saliva. 1. The composition and output of sheep's saliva. Biochemistry Journal, v.43, p.99, 1949.

MOORE, J.E.; MOTT, G.O. Structural inhibitor of quality in tropical grasses. In: MATCHES, A.G. (Ed.). Antiquality components of forage. New York: Science Society of América, 1973. p.93-98.

MORENZ, M.J.F. Frações nitrogenadas, métodos de processamento de amostras e degradabilidade in situ de 
gramíneas tropicais. Campos dos Goytacazes: Universidade Estadual do Norte Fluminense, 2003. 63p. Dissertação (Mestrado em Zootecnia) - Universidade Estadual do Norte Fluminense, 2003.

PELL, A.N.; SCHOFIELD, P. Computerized monitoring of gas production to measure forage digestion in vitro. Journal of Dairy Science, v.76, n.4, p.1063-1073, 1993.

RAYMOND, W.F. The nutritive value of forage crops. Advances in Agronomy, v.21, p.1-103, 1969.

RODRIGUES, L.R.A.; REIS, R.A. Conceituação e modalidades de sistemas intensivos de pastejo rotacionado. In: SIMPÓSIO SOBRE MANEJO DA PASTAGEM, 1997, Piracicaba. Anais... Piracicaba: Fundação de Estudos Agrários Luiz de Queiroz, 1997. p.1-24.

ROWLAND A.P.; ROBERTS J.D. Lignin and celulose fraction in decomposition studies using acid-detergent fiber methods. Communications in Soil Science and Plant Analysis, v.25. p.3-4, 269-277, 1994.

SCHOFIELD, P.; PITT, R.E.; PELL, A.N. kinetics analysis of the neutral detergent-soluble carbohydrates fraction of legumes and grasses. Journal of Animal Science, v.73, n.4, p.2980-2991, 1994.
SILVA, D.J. Análises de alimentos (métodos químicos e biológicos). 2.ed. Viçosa, MG: Imprensa Universitária, 1990. $165 p$.

SNIFFEN, C.J.; O’CONNOR, J.D.; van SOEST, P.J. et al. A ne carbohydrate and protein system for evaluating cattle diets: II. Carbohydrate and protein availability. Journal of Animal Science, v.70, n.12, p.3562-3577, 1992

SOUZA, G.S. Introdução aos modelos de regressão linear e não-linear. Brasília: Embrapa Cerrados, 1998. 505p.

TILLEY, J.M.A.; TERRY, R.A. A two-stage tecnique for the in vitro digestion of forage crops. Journal British Grassland Science, v.18, n.2, p.104-111, 1963.

Van SOEST, P.J. Nutritional ecology of the ruminant. Ithaca: Cornell University, 1994. 476p.

WEISS, W.P. Energy prediction equations for ruminant feeds In: CORNELL NUTRITION CONFERENCE FOR FEED MANUFACTURERS, 61., 1999, Ithaca. Proceedings... Ithaca: Cornell University, 1999. p.176-185. 